Genetic and Molecular Characterization of Mating Type Genes in Cochliobolus sativus Author(s): Shaobin Zhong and Brian J. Steffenson

Source: Mycologia, Vol. 93, No. 5 (Sep. - Oct., 2001), pp. 852-863

Published by: Taylor \& Francis, Ltd.

Stable URL: http://www.jstor.org/stable/3761751

Accessed: 11-06-2017 16:50 UTC

\title{
REFERENCES
}

Linked references are available on JSTOR for this article: http://www.jstor.org/stable/3761751?seq=1\&cid=pdf-reference\#references_tab_contents You may need to log in to JSTOR to access the linked references.

JSTOR is a not-for-profit service that helps scholars, researchers, and students discover, use, and build upon a wide range of content in a trusted digital archive. We use information technology and tools to increase productivity and facilitate new forms of scholarship. For more information about JSTOR, please contact support@jstor.org.

Your use of the JSTOR archive indicates your acceptance of the Terms \& Conditions of Use, available at http://about.jstor.org/terms

Taylor \& Francis, Ltd. is collaborating with JSTOR to digitize, preserve and extend access to Mycologia 


\section{Genetic and molecular characterization of mating type genes in Cochliobolus sativus}

\author{
Shaobin Zhong \\ Brian J. Steffenson ${ }^{1}$ \\ Department of Plant Pathology, North Dakota State \\ University, Fargo, North Dakota 55108 \\ Current address: Department of Plant Pathology, \\ University of Minnesota, St. Paul, Minnesota 58105
}

\begin{abstract}
Genetic and molecular approaches were used to characterize the mating type (MAT) genes in Cochliobolus sativus. One hundred and four ascospore progeny derived from a cross of C. sativus isolates ND93-1 (MAT-1) $\times$ ND90Pr (MAT-2) were backcrossed with their parents to determine mating type, but only five progeny produced pseudothecia with asci and/or ascospores. When degenerate primers from the conserved high mobility group (HMG) protein domain encoded by the MAT-2 gene in Cochliobolus species were used in polymerase chain reaction (PCR) with genomic DNA of C. sativus as templates, an amplicon of predicted size was amplified only from MAT-2 isolates. The presence of a MAT-2 homolog in these MAT-2 isolates was confirmed by Southern hybridization with the HMG box as a probe. Additionally, the presence or absence of the HMG homolog in the progeny segregated in a $1: 1$ ratio, as expected for the single gene control of mating type. Using primers based on the conserved regions at the $5^{\prime}$ and $3^{\prime}$ flanks of the idiomorphs in the $M A T$ genes of other Cochliobolus species, the fulllength MAT-1 and MAT-2 idiomorphs were cloned by PCR from $C$. sativus isolates ND93-1 and ND90Pr, respectively. DNA sequence analysis indicated that these two idiomorphs are organized in a manner similar to their respective counterparts in other Cochliobolus species. DNA hybridization and PCR amplification analysis of 54 field isolates of $C$. sativus collected worldwide showed that both mating types exist in populations around the world. The low frequency of successful backcrosses of progeny to parents in the ND93-1 $\times$ ND90Pr cross, combined with the fact that many crosses between isolates of opposite mating type are unsuccessful, suggests that genetic factors other than MAT genes affect the fertility of the fungus.
\end{abstract}

Accepted for publication February 22, 2001.

${ }^{1}$ Corresponding author, Email: bsteffen@umn.edu
Key Words: DNA binding protein, high mobility group, infertility

\section{INTRODUCTION}

In all Ascomycetes tested to date, sexual reproduction is controlled by mating type (MAT) genes. Knowledge of the structure and function of these genes is essential for understanding the evolution of the mating system and pathogenicity in plant pathogenic fungi (Turgeon 1998). Using a molecular genetic approach, MAT genes were recently cloned from several ascomycetous plant pathogens in the genus Cochliobolus, including C. heterostrophus (Turgeon et al 1993), C. carbonum (Christiansen et al 1997), and C. victoriae (Christiansen et al 1997). Analysis of the molecular organization of these MAT genes revealed that the two opposite mating type genes occupy the same locus but consist of completely unrelated sequences known as idiomorphs (Metzenberg and Glass 1990). MAT-1 idiomorphs of Cochliobolus species encode a DNA-binding protein (alpha domain), which corresponds to one of several proteins encoded by the $m t A$ idiomorph of Neurospora crassa and mat- idiomorph of Podospora anserina (Turgeon et al 1993). MAT-2 idiomorphs encode a different DNA-binding protein (high mobility group [HMG]), which is also encoded by the $m t a-1$ idiomorph of $N$. crassa and mat+ idiomorph of $P$. anserina (Turgeon et al 1993). These alpha and HMG domains are highly conserved across all Ascomycetes studied to date. Although the similarity between opposite idiomorphs of mating type genes in Cochliobolus is low (33\%), high sequence conservation was found in the flanking regions (Christiansen et al 1997; Turgeon 1998).

Cochliobolus sativus (Ito \& Kurib.) Drechs. ex Dastur [anamorph: Bipolaris sorokiniana (Sacc. in Sorok.) Shoem.] is a plant pathogen of worldwide importance causing spot blotch, common root rot, and black point of barley and wheat. The sexual stage of the fungus can be induced in the laboratory (Tinline 1951, Shoemaker 1955), but has not been found in nature (Tinline 1988). Like other heterothallic Ascomycetes, two mating types designated $\mathrm{A}$ and $\mathrm{a}$, are required for successful matings (Tinline 1988). Early genetic studies indicated that a single locus controls 
TABLE I. Cochliobolus sativus isolates with known mating type used in this study

\begin{tabular}{lllc}
\hline \hline Isolate & $\begin{array}{c}\text { Geographic } \\
\text { origin }\end{array}$ & \multicolumn{1}{c}{ Source } & $\begin{array}{c}\text { Mating } \\
\text { type }^{\mathrm{b}}\end{array}$ \\
\hline ND93-1 & North Dakota & B. J. Steffenson & 1 \\
ND90Pr & North Dakota & B. J. Steffenson & 2 \\
D9 & Canada & R. D. Tinline & 2 \\
D14 & Canada & R. D. Tinline & 2 \\
D8 & Canada & R. D. Tinline & 1 \\
A20 & Canada & R. D. Tinline & 2 \\
A18 & Canada & R. D. Tinline & 1 \\
K3 & Canada & R. D. Tinline & 2 \\
J1-15 & Canada & R. D. Tinline & 1 \\
R3-11 & Canada & R. D. Tinline & 1 \\
\hline
\end{tabular}

a Mating type of isolates ND93-1 and ND90Pr was determined by Valjavec-Gratian and Steffenson (1997b); mating type of the remaining isolates was determined by R. D. Tinline (Harding and Tinline 1983).

b MAT-1 and MAT-2 correspond to the mating type designated as a and A, respectively, by Tinline (1951).

mating type in C. sativus (Tinline 1951, Tinline and Dickson 1958), however, the fertility of matings among field-collected isolates is highly variable (Kline and Nelson 1968, Harding and Tinline 1983). The objectives of this study were to study the genetics of MAT genes in a $C$. sativus cross, and to clone the mating type idiomorphs by PCR amplification using primer pairs corresponding to the conserved regions of the MAT genes in other Cochliobolus species.

\section{MATERIALS AND METHODS}

Fungal isolates and crosses.-Isolates used in this study included the C. sativus parental isolates ND90Pr and ND931,104 progeny derived from their hybridization, 8 experimental isolates (TABLE I), and 54 field isolates collected around the world (TABLE II). Methods for producing the ND90Pr $\times$ ND93-1 cross and information on the parental isolates and resulting progeny population are described in Valjavec-Gratian and Steffenson (1997b). The mating type of isolate ND90Pr was determined to be MAT-2 (formerly A) by crossing tests with the $C$. sativus tester isolates A18 (MAT-1, formerly a) and A20 (MAT-2, formerly A), provided by K. L. Bailey, Agriculture \& Agri-Food Canada Research Station, Saskatoon, Saskatchewan. The mating type of isolate ND93-1 was determined to be MAT-1, based on the fact that it is compatible with ND90Pr (Valjavec-Gratian and Steffenson 1997b). To determine the mating type of the progeny isolates, the two parents ND93-1 and ND90Pr were crossed with each of the progeny using a method modified from Tinline (1951) and described by Valjavec-Gratian and Steffenson (1997b). For each progeny isolate, at least two mating attempts were made to each parent. Selfings of 20 progeny isolates and matings between the original parental isolates ND90Pr and ND93-1 were included as con- trols in the experiment. For each backcross or cross, 20 to 30 pseudothecia-like structures were crushed and checked for the presence of asci and ascospores

DNA isolation, manipulation, and hybridization.-Plasmid DNA isolation and subcloning were according to Sambrook et al (1989). Genomic DNA was isolated from C. sativus isolates using the method described by Yoder (1988). For Southern hybridization, genomic DNA of $C$. sativus was digested with restriction enzymes according to the conditions recommended by the manufacturer (New England Biolabs, Beverly, Massachusetts). Digested DNA fragments (2 $\mu \mathrm{g}$ per lane) were separated on $0.9 \%$ agarose gels, treated with $0.25 \mathrm{~N} \mathrm{HCl}$ for $10 \mathrm{~min}$, and blotted to Hybond+ filters in $0.4 \mathrm{~N} \mathrm{NaOH}$ for $12-18 \mathrm{~h}$. Filters were pre-hybridized at 65 $\mathrm{C}$ in a pre-hybridization buffer $\left(0.5 \mathrm{M} \mathrm{NaPO}_{4}, 7 \% \mathrm{SDS}\right.$, and $1 \%$ BSA) for 2-3 hours before a DNA probe was added. Two clones were used as probes. One was the HMG box cloned into the TA cloning vector (Invitrogen, Carlsbad, California), and the other was a $0.25 \mathrm{~kb} H i n d I I I-E c o R I$ fragment sub-cloned from the MAT-1 gene of isolate ND93-1. These clones were labeled with $\alpha-\left[{ }^{32} \mathrm{P}\right] \mathrm{dCTP}$ by the random hexamer labeling method (Feinberg and Vogelstein 1983). DNA-DNA hybridization was carried out at $65 \mathrm{C}$ for at least 16 hours, and the filters were sequentially washed in $2 \times$ $\mathrm{SSC} / 1 \% \mathrm{SDS}$ at $65 \mathrm{C}$ for $10 \mathrm{~min}, 1 \times \mathrm{SSC} / 0.5 \% \mathrm{SDS}$ at 65 $\mathrm{C}$ for $10 \mathrm{~min}$, and $0.5 \times \mathrm{SSC} / 0.25 \% \mathrm{SDS}$ at $65 \mathrm{C}$ for one hour. Filters were then exposed to Kodak XAR- 5 film for 16-96 $\mathrm{hr}$ depending on the strength of the radioisotope signal. Labeled filters were stripped before reuse by washing in $0.5 \% \mathrm{SDS}$ at $95 \mathrm{C}$ for $1-2 \mathrm{~min}$.

PCR amplification.-The degenerate primer pair 5'AAGGCNCCNCGYCCNATGAAC-3' (ChHMG1) and 5'CTNGGNGTGTAYTTGTAATTNGG-3' (ChHMG2), designed by Arie et al (1997), was used in PCR to amplify the HMG box homolog from isolate ND90Pr. Specific primers (CsPrimer1 and CsPrimer2) based on the C. sativus HMG box sequence were used to amplify the HMG box from other C. sativus isolates. Other primers (TABLE III) corresponding to the highly conserved regions at the $5^{\prime}$ and $3^{\prime}$ ends of the mating-type genes in several Cochliobolus species (C. heterostrophus, C. carbonum, and C. victoriae) were used to amplify the flanking regions of the HMG box and the entire MAT idiomorphs. Amplification was performed in a $50 \mu \mathrm{L}$ PCR solution, which contained $1 \times$ buffer $(10 \mathrm{mM}$ Tris- $\mathrm{HCl} \mathrm{pH} 8.4$ and $50 \mathrm{mM} \mathrm{KCl}), 1.5 \mathrm{mM} \mathrm{MgCl}_{2}, 200 \mu \mathrm{M}$ dNTP, 1.0 unit of Taq DNA polymerase (Promega, Madison, Wisconsin), $36 \mathrm{ng}$ of each primer, and $25 \mathrm{ng}$ of template DNA. Denaturation at $95 \mathrm{C}$ for $2 \mathrm{~min}$ was followed by 30 cycles of $94 \mathrm{C}$ for $1 \mathrm{~min}, 55 \mathrm{C}$ for $30 \mathrm{~s}$, and $72 \mathrm{C}$ for $1 \mathrm{~min}$ in a thermocycler (PTC-100 ${ }^{\mathrm{TM}}$ Programmable Thermal Controller, MJ Research Inc., Watertown, Massachusetts). PCR products were separated in $1.4 \%$ agarose gels in $1 \times$ TAE buffer, stained with ethidium bromide, and photographed

Cloning, sequencing, and analysis of PCR products.-PCR products were cloned into the vector PCR2.1 using the TA cloning kit (Invitrogen, Carlsbad, California) according to the manufacturer's instructions. The inserts were se- 
TABLE II. Field isolates of Cochliobolus sativus assessed for mating type by DNA hybridization and PCR amplification

\begin{tabular}{|c|c|c|c|c|}
\hline Isolate & Year collected & Geographic origin (location/state/country) & Source & $\begin{array}{l}\text { Mating } \\
\text { type }^{\mathrm{a}}\end{array}$ \\
\hline $\mathrm{ND} 85 \mathrm{~F}$ & 1985 & Walsh/ND/USA & B. J. Steffenson & 1 \\
\hline R002 & 1976 & Walsh/ND/USA & R. W. Stack & 1 \\
\hline ND89-1 & 1989 & Cass/ND/USA & B. J. Steffenson & 2 \\
\hline ND89-8 & 1989 & Emmons/ND/USA & B. J. Steffenson & 1 \\
\hline ND89-25 & 1989 & Rolette/ND/USA & B. J. Steffenson & 2 \\
\hline ND89-33 & 1989 & Mountrail/ND/USA & B. J. Steffenson & 2 \\
\hline ND89-37 & 1989 & Dunn/ND/USA & B. J. Steffenson & 1 \\
\hline ND89-38 & 1989 & Mercer/ND/USA & B. J. Steffenson & 2 \\
\hline ND89-40 & 1989 & Sheridan/ND/USA & B. J. Steffenson & 2 \\
\hline ND91-Bowman & 1991 & Minot/ND/USA & B. J. Steffenson & 2 \\
\hline SD91-7 & 1991 & Roberts/SD/USA & B. J. Steffenson & 1 \\
\hline MN91-11 & 1991 & Traverse/MN/USA & B. J. Steffenson & 1 \\
\hline MN92-5 & 1992 & Polk/MN/USA & B. J. Steffenson & 2 \\
\hline MN92-6 & 1992 & Ramsey/MN/USA & B. J. Steffenson & 1 \\
\hline ND92-1 & 1992 & Cass/ND/USA & B. J. Steffenson & 1 \\
\hline ND92-2 & 1992 & Cass/ND/USA & B. J. Steffenson & 2 \\
\hline ND92-8 & 1992 & Stutsman/ND/USA & B. J. Steffenson & 1 \\
\hline ND92-10 & 1992 & Logan/ND/USA & B. J. Steffenson & 1 \\
\hline ND92-11 & 1992 & Emmons/ND/USA & B. J. Steffenson & 1 \\
\hline ND93-11 & 1993 & Cavalier/ND/USA & B. J. Steffenson & 1 \\
\hline ND93-12 & 1993 & Ramsey/ND/USA & B. J. Steffenson & 2 \\
\hline ND93-18 & 1993 & Cass/ND/USA & B. J. Steffenson & 1 \\
\hline ND95-17 & 1995 & Towner/ND/USA & B. J. Steffenson & 2 \\
\hline ND95-31 & 1995 & Hettinger/ND/USA & B. J. Steffenson & 1 \\
\hline KB001 & 1993 & Cass/ND/USA & B. J. Steffenson & 1 \\
\hline KB002 & 1993 & Cass/ND/USA & B. J. Steffenson & 1 \\
\hline KB005 & 1993 & Cass/ND/USA & B. J. Steffenson & 1 \\
\hline KB008 & 1993 & Cass/ND/USA & B. J. Steffenson & 1 \\
\hline KB361 & 1994 & Larimer/CO/USA & B. J. Steffenson & 1 \\
\hline KB362 & 1994 & Larimer/CO/USA & B. J. Steffenson & 1 \\
\hline KB363 & 1994 & Larimer/CO/USA & B. J. Steffenson & 2 \\
\hline KB364 & 1994 & Larimer/CO/USA & B. J. Steffenson & 1 \\
\hline JPN95-1 & 1995 & b__/Shikoku/Japan & B. J. Steffenson & 2 \\
\hline JPN95-2 & 1995 & -/Shikoku/Japan & B. J. Steffenson & 2 \\
\hline CHN95-1 & 1995 & Hongshan/Zhejiang/China & B. J. Steffenson & 2 \\
\hline CHN95-2 & 1995 & Hongshan/Zhejiang/China & B. J. Steffenson & 1 \\
\hline ND97-Foster & 1997 & Towner/ND/USA & B. J. Steffenson & 1 \\
\hline VA98-1 & 1998 & Nottoway/VA/USA & B. J. Steffenson & 1 \\
\hline Brier & - & -/_/Canada & R. D. Tinline & 2 \\
\hline POL97-KD31 & 1997 & $-/-/$ Poland & J. Chelkowski & 1 \\
\hline POL97-KD32 & 1997 & $-/-/$ Poland & J. Chelkowski & 2 \\
\hline POL97-KD33 & 1997 & $-/-/$ Poland & J. Chelkowski & 1 \\
\hline POL97-KD34 & 1997 & $-/-/$ Poland & J. Chelkowski & 2 \\
\hline POL97-KD35 & 1997 & $-/-/$ Poland & J. Chelkowski & 2 \\
\hline POL97-KD36 & 1997 & $-/-/$ Poland & J. Chelkowski & 2 \\
\hline BRZ97-PF1 & 1997 & Passo Fundo/Rio Grande do Sul/Brazil & G. Arias & 2 \\
\hline BRZ97-PF2 & 1997 & Passo Fundo/Rio Grande do Sul/Brazil & G. Arias & 2 \\
\hline BRZ97-PF3 & 1997 & Passo Fundo/Rio Grande do Sul/Brazil & G. Arias & 2 \\
\hline NZ98-Pickering & 1997 & $-/-/$ New Zealand & R. Pickering & 1 \\
\hline URY98-Gamba18 & 1997 & $-/-/$ Uruguay & F. Gamba & 1 \\
\hline URY98-Gamba30 & 1997 & -/_/Uruguay & F. Gamba & 1 \\
\hline URY98-Gamba51 & 1997 & -/-/Uruguay & F. Gamba & 2 \\
\hline URY98-Gamba54 & 1997 & $-/-/$ Uruguay & F. Gamba & 2 \\
\hline URY98-Gamba55 & 1997 & $-/-/$ Uruguay & F. Gamba & 2 \\
\hline
\end{tabular}

a Mating types were determined by DNA hybridization with MAT-1 and MAT-2 specific probes and PCR amplification with primer pair ChPrimer1+ChPrimer2.

${ }^{\mathrm{b}}$ Unknown or not applicable. 


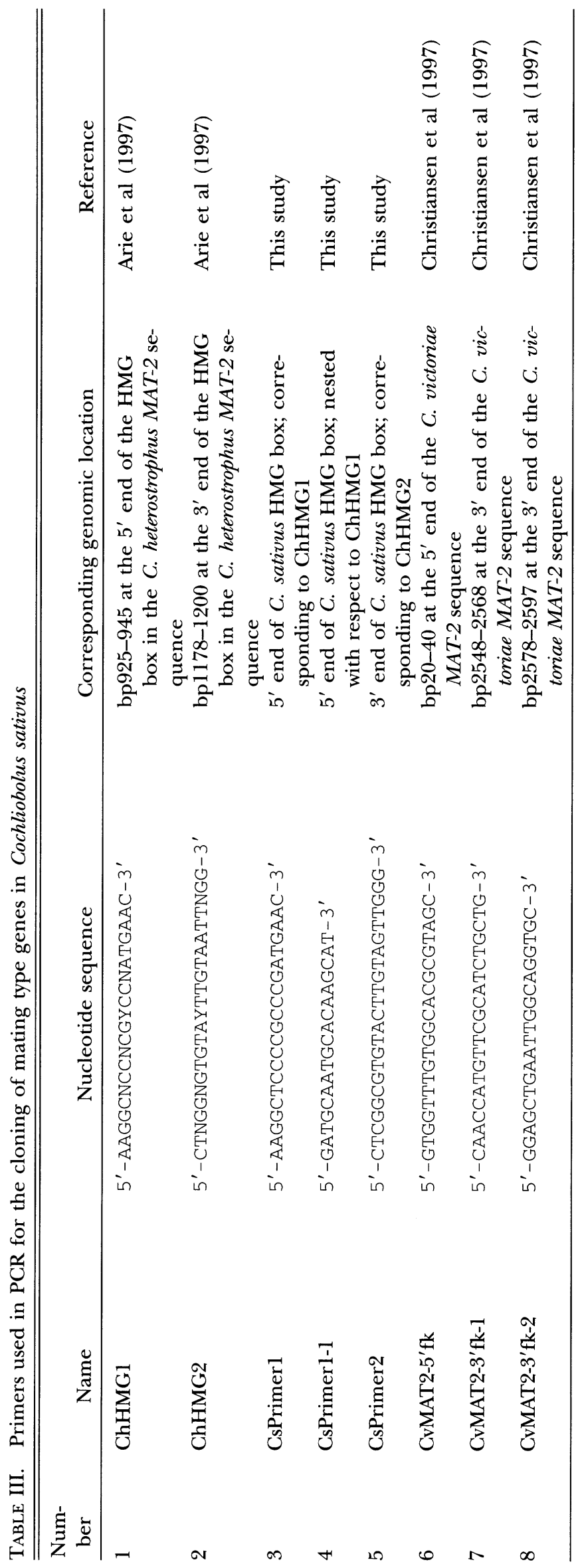




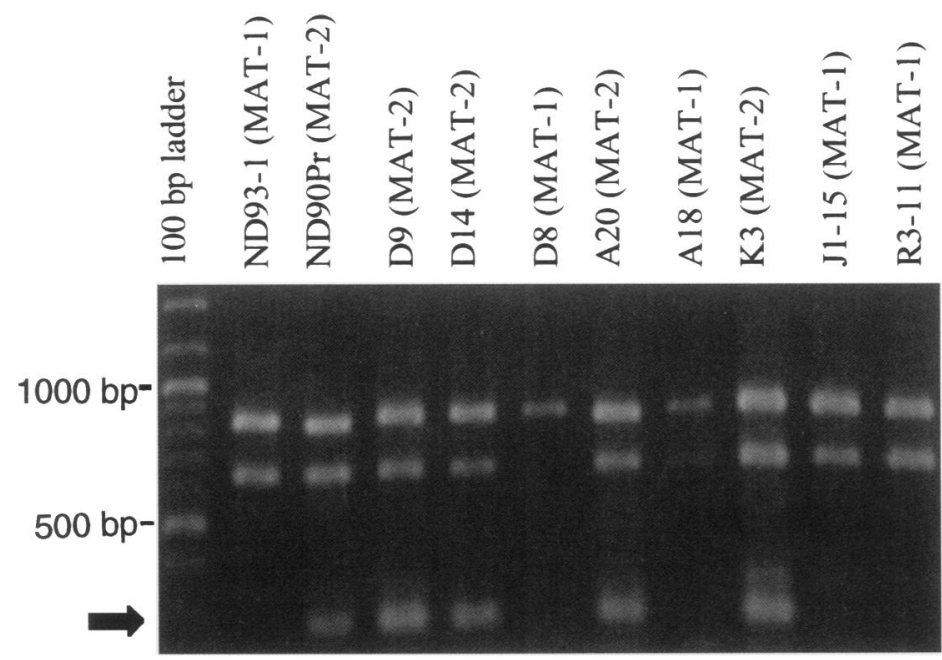

FIG. 1. Amplification of the HMG box in Cochliobolus sativus isolates. Primer pair ChHMG1 and ChHMG2 was used in PCR with genomic DNA of isolates ND93-1 and ND90Pr. Primer pair CsPrimer1 and CsPrimer2 was used in PCR with genomic DNA of the other isolates. PCR products were separated in a $1.4 \%$ agarose gel and stained with ethidium bromide.

quenced using the SequiTherm EXCEL ${ }^{\mathrm{TM}}$ II DNA Sequencing Kit (Epicentre, Madison, Wisconsin) with a LI-COR ${ }^{8}$ Sequencer (LI-COR Inc., Lincoln, Nebraska). When the inserts were larger than $800 \mathrm{bp}$ in size, sub-cloning was performed before sequencing. Double strand sequencing was performed for all clones. The computer software program MacVector 6.0 (Oxford Molecular, London) was used to assemble, align, and analyze the sequences. Sequence data were subjected to similarity searches against the GenBank databases using the BLAST search programs of Altschul et al (1997). The DNA sequences of the two mating type idiomorphs of $C$. sativus have been deposited in GenBank databases with the accession numbers AF275373 and AF275374 for MAT-1 and MAT-2, respectively.

\section{RESULTS}

Testing of mating types of progeny by backcrossing.One hundred and four ascospore progeny isolates derived from cross ND93-1 × ND90Pr (Valjavec-Gratian and Steffenson 1997b) were tested for mating compatibility by backcrossing to each of the respective parents. Only five backcross pairings produced pseudothecia containing asci, and all were with parental isolate ND90Pr. No fertile pseudothecia were found in backcrosses with isolate ND93-1. Even in matings where asci were observed, the frequency of pseudothecia with asci was low, ranging from $7 \%$ to $10 \%$. Asci with ascospores were observed in only two of the matings, and the number of ascospores in each ascus ranged from one to two. Pseudothecia-like structures, which were called protothecia by Shoemaker (1955), were observed in $34 \%$ of the matings with isolate ND93-1 and $65 \%$ of the matings with isolate ND90Pr where no asci and/or ascospores were observed. Protothecia also appeared in the fer- tile crosses and in the selfings (when a single isolate was plated). The protothecia superficially resembled mature pseudothecia, but lacked differentiation inside the centrum in addition to the absence of asci and/or ascospores. Eighteen percent of the progeny isolates did not produce any fruiting structures in the matings with either of the parents. In control crosses between isolates ND93-1 and ND90Pr, asci were observed in $35 \%$ of the pseudothecia evaluated, and only $23 \%$ of the asci contained ascospores, with the number ranging from one to five per ascus

Amplification of the HMG box from $\mathrm{C}$. sativus.-Three PCR products were amplified from isolate ND90Pr, and two were amplified from isolate ND93-1 with primers ChHMG1 and ChHMG2 (FIG. 1). A DNA fragment of approximately $270 \mathrm{bp}$ in size was only present in isolate ND90Pr. Cloning and sequencing of this DNA fragment revealed a $91 \%$ identity to the C. heterostrophus HMG box (Turgeon et al 1993) and a $99 \%$ identity to the HMG box homolog amplified from C. sativus isolate A20 (MAT-2) (Arie et al 1997).

Primers CsPrimer1 and CsPrimer2 (TABLE III) were designed based on the sequence of the PCR product (HMG box) specific for isolate ND90Pr. These primers were used in PCR amplification with genomic DNA of other $C$. sativus isolates whose mating types were previously characterized (TABLE I). A PCR product of the expected size (270 bp) was amplified only from DNA of MAT-2 isolates (FIG. 1). Probing of Southern blots with the cloned HMG box revealed a hybridization band present only in MAT-2 isolates (FIG. 2).

The primer pair CsPrimer1 +2 was also used for PCR amplification with genomic DNAs of the asco- 


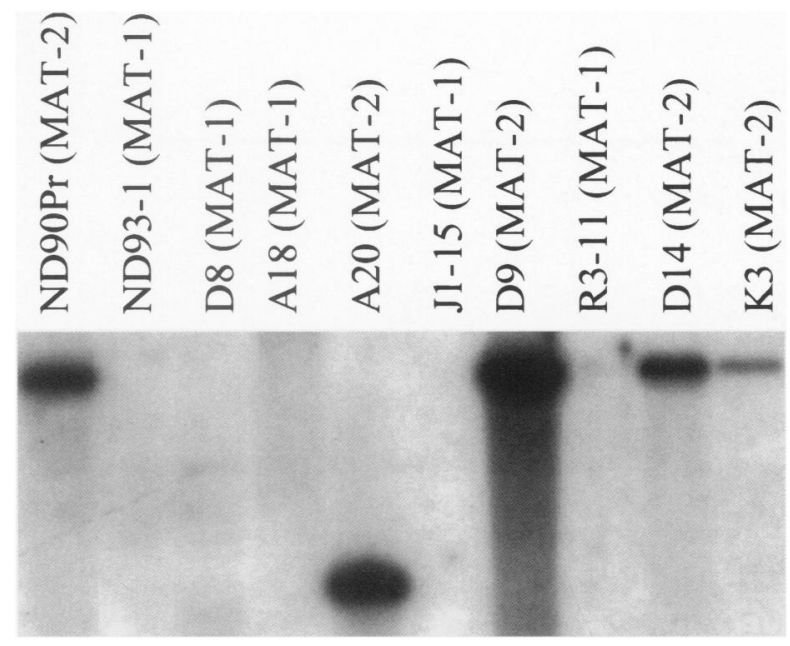

FIG. 2. Hybridization of the HMG box to genomic DNAs of Cochliobolus sativus isolates of known mating type. Genomic DNAs from C. sativus isolates were digested with EcoRV, separated in a $0.9 \%$ agarose gel, blotted, and probed with the HMG box as a probe. Note that a hybridization signal was only present in MAT-2 isolates. Isolates ND90Pr, D9, D14, and K3 exhibited a hybridization band of about $14.8 \mathrm{~kb}$, whereas isolate A20 had a polymorphic band of about $4.5 \mathrm{~kb}$.

spore progeny serving as templates. A PCR product of the expected size $(270 \mathrm{bp})$ was produced in 53 of the 104 progeny isolates. The other 51 progeny isolates, including the five that were compatible with isolate ND90Pr in the backcrossing experiments (see above), did not produce this DNA fragment in the PCR amplification. Southern hybridization of the HMG box to genomic DNAs from the progeny showed that a hybridization band was only present in the progeny isolates that produced the HMG amplicon (FIG. 3). The segregation of progeny for the presence or absence of the HMG box was not significantly different from a $1: 1$ ratio $\left(\chi^{2}=0.03, P=0.88\right)$ as expected for the segregation of a single locus in a haploid organism.

Cloning of C. sativus MAT-2 and MAT-1 idiomorphs.Comparison of the MAT genes cloned from other Cochliobolus species (e.g., C. heterostrophus, C. carbon- um, and C. victoriae) (Turgeon et al 1993, Christiansen et al 1997) revealed highly conserved regions at both the $5^{\prime}$ and $3^{\prime}$ flanks of the idiomorphs. Thus, primers complementary to these conserved regions were designed and used in combination with CsPrimer1-1 and CsPrimer2 for PCR amplification of the MAT-2 idiomorph from C. sativus (FIG. 4). A PCR product of approximately $1.3 \mathrm{~kb}$ in size was amplified from genomic DNA of isolate ND90Pr using primers CvMAT2-5' $\mathrm{fk}$ and CsPrimer2 (FIG. 5, lane 1). Cloning and sequencing of this product showed that it contained the HMG box and the $5^{\prime}$ flanking region. In the PCR amplification with primers CsPrimer1-1 and CvMAT2-3' $\mathrm{fk}-2$ and DNA of isolate ND90Pr, a fragment of approximately $1.3 \mathrm{~kb}$ was amplified, which contained the HMG box and the $3^{\prime}$ flanking region (FIG. 5, lane 3). Alignment of DNA sequences of the two PCR products produced a DNA sequence of $2547 \mathrm{bp}$, which combined the HMG box and its 5'and 3' flanking regions. The entire DNA sequence was amplified when primers CvMAT2-5' $\mathrm{fk}$ and CvMAT2-3' $\mathrm{fk}-2$ and genomic DNA of isolate ND90Pr were used for the PCR amplification (FIG. 5, lane 4). PCR with genomic DNA of isolate ND90Pr and primers CsPrimer1-1 and CvMAT2-3' fk-1 generated a product containing the HMG box but a shorter $3^{\prime}$ flanking region (FIG. 5, lane 2).

When primers CvMAT2-5' fk and CvMAT2-3' fk-2 were used to amplify DNA from isolate ND93-1 (MAT-1), a fragment of approximately $2.7 \mathrm{~kb}$ was generated (FIG. 5, lane 5). Cloning and sequencing of this PCR product revealed that it is highly similar and presumably homologous to the MAT-1 idiomorph cloned from C. heterostrophus and C. carbonum (Turgeon et al 1993, Christiansen et al 1997) (see below).

Sequence analysis.-DNA sequences of the MAT-1 (2681 bp) (AF275373) and MAT-2 (2547 bp) (AF275374) idiomorphs cloned from the two C. sativus isolates ND93-1 and ND90Pr, respectively, were analyzed and compared with those of $C$. heterostrophus (Turgeon et al 1993, Wirsel et al 1998). As in C. heterostrophus, the overall nucleotide identity be-

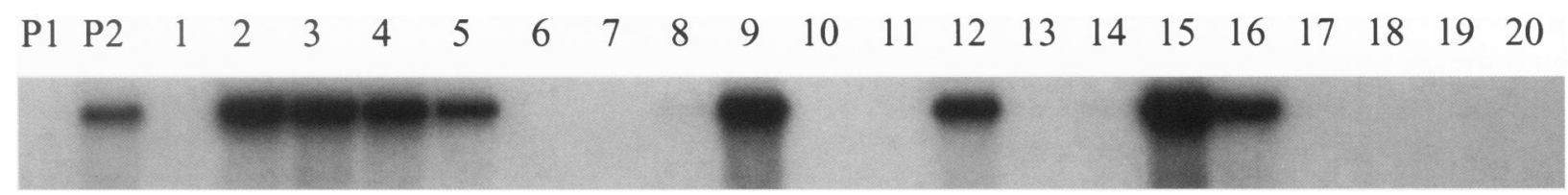

FIG. 3. Hybridization of HMG box to genomic DNAs of a subset of Cochliobolus sativus progeny isolates derived from the ND93-1 $\times$ ND90Pr cross. Genomic DNAs from the progeny isolates were digested with EcoRV, separated in a $0.9 \%$ agarose gel, blotted and probed with the HMG box as a probe. Parental isolates ND93-1 (P1) and ND90Pr (P2) are MAT-1 and MAT-2, respectively. Progeny isolates $1,6,7,8,10,11,13,14,17,18,19$, and 20 are MAT-1. Progeny isolates 2, 3, 4, 5, 9, 12, 15 , and 16 are MAT-2. 


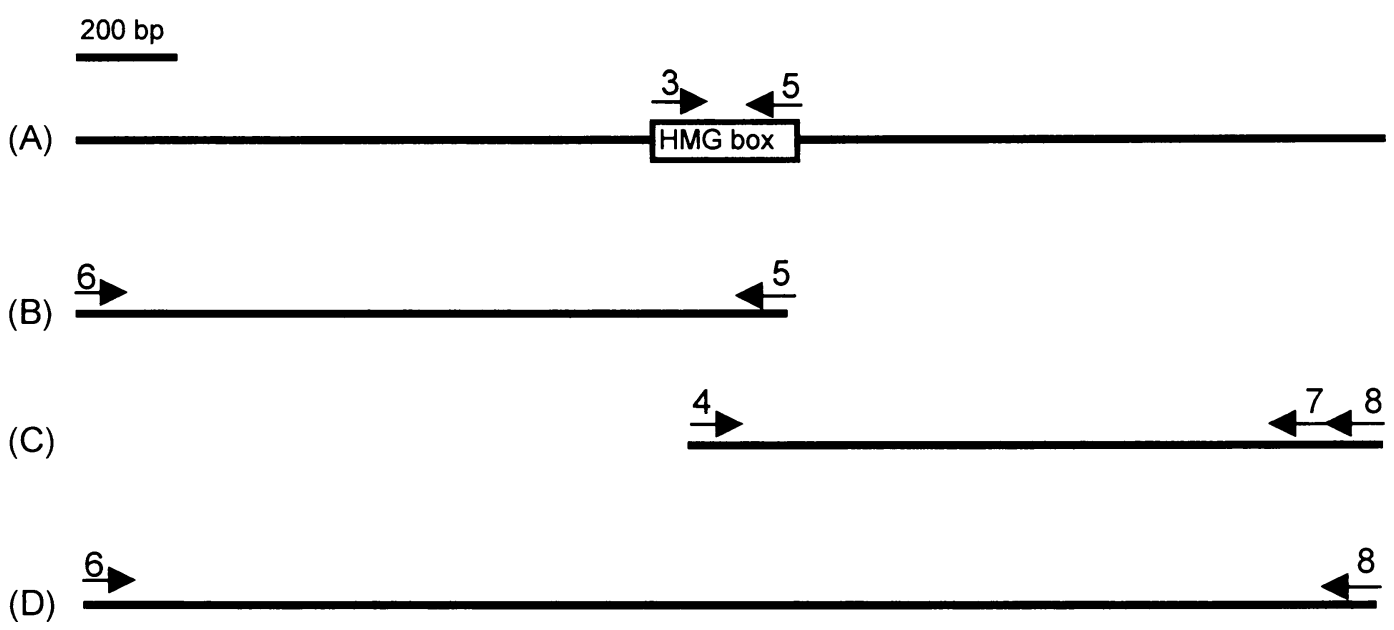

FIG. 4. Diagram showing PCR cloning of the MAT-2 gene in Cochliobolus sativus. The arrows represent primers and the direction for amplification. The number above each arrow corresponds to the primer number listed in TABLE III. A). Amplification of the HMG box using primers 3 and 5. B). Amplification of the HMG box and its $5^{\prime}$ flanking region with primers 5 and 6. C). Amplification of the HMG box and its $3^{\prime}$ flanking region with primers 4 and 7 or 4 and 8 , respectively. D). Recovery of the entire MAT-2 idiomorph with primers 6 and 8 .

tween the idiomorphs of the two opposite mating type isolates in C. sativus was low $(<40 \%)$, whereas the $5^{\prime}$ and $3^{\prime}$ flanking regions were $96 \%$ and $97 \%$ similar, respectively (TABLE IV). Sequence comparison of the MAT genes from C. sativus and C. heterostrophus revealed a $90 \%$ nucleotide identity for both MAT-1 and MAT-2 (TABLE IV).

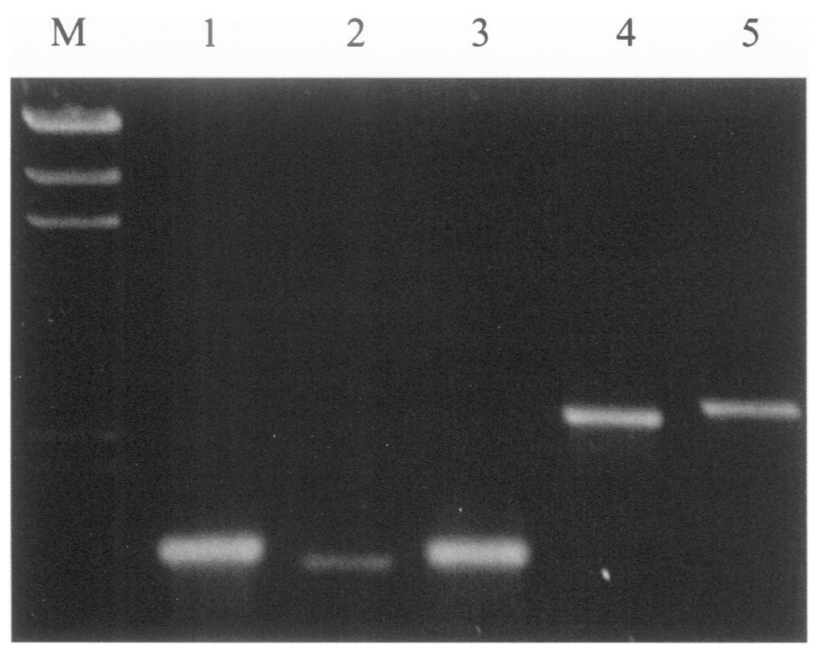

FIG. 5. PCR products amplified with different primer pairs from genomic DNA of Cochliobolus sativus isolates ND90Pr and ND93-1. Lane 1) DNA fragment amplified from ND90Pr with primers CvMAT2-5' fk + CsPrimer2, 2) DNA fragment amplified from ND90Pr with primers CsPrimer1-1+CvMAT2-3' fk-1, 3) DNA fragment amplified from ND90Pr with primers CsPrimer1-1 + CvMAT2-3' fk-2, 4) DNA fragment amplified from ND90Pr with primers CvMAT-2-5' fk + CvMAT2-3' fk-2, 5) DNA fragment amplified from ND93-1 with primers CvMAT2-5' fk + CvMAT2$3^{\prime} \mathrm{fk}-2 . \mathrm{M}$ is DNA size marker (Hind III-digested $\lambda$ DNA).
Several open reading frames (ORFs) were found in the MAT idiomorphs of C. sativus. The C. sativus MAT-1-specific ORF is interrupted by an intron, which was found at the same position as the intron in the C. heterostrophus MAT-1 (Turgeon et al 1993). A putative intron also was found in the $C$. sativus MAT-2-specific ORF, similar to the $C$. heterostrophus MAT-2 (Turgeon et al 1993). Removal of the introns generated continuous ORFs encoding 378 amino acids for MAT-1 and 337 amino acids for MAT-2 that were nearly the same length as their respective counterparts in C. heterostrophus. Similarity searches against the GenBank databases indicated that the translated proteins contained DNA binding domains (an alpha domain for MAT-1 and a HMG motif for $M A T-2)$ that have been found in the proteins encoded by MAT genes from several other filamentous fungi including Cochliobolus species (for review see Turgeon 1998). The alpha domain and HMG motif in C. sativus showed three and four amino acid differ-

TABLE IV. Nucleotide identity (\%) between $M A T$ genes of Cochliobolus sativus and C. heterostrophus

\begin{tabular}{|c|c|c|c|}
\hline $\begin{array}{l}\text { MAT genes } \\
\text { compared }^{\mathrm{a}}\end{array}$ & $\begin{array}{c}5^{\prime} \text { flank } \\
(739 \mathrm{bp})^{\mathrm{b}}\end{array}$ & $\begin{array}{l}3^{\prime} \text { flank } \\
(658 \mathrm{bp})^{c}\end{array}$ & Idiomorph \\
\hline ChMAT-1/ChMAT-2 & 99.5 & 99.0 & $<40.0$ \\
\hline CsMAT-1/CsMAT-2 & 96.0 & 97.0 & $<40.0$ \\
\hline$C h M A T-1 / C s M A T-1$ & 83.5 & 85.0 & 90.0 \\
\hline ChMAT-2/CsMAT-2 & 83.0 & 85.0 & 90.0 \\
\hline
\end{tabular}

${ }^{a} \mathrm{Ch}=C$. heterostrophys; $\mathrm{Cs}=C$. sativus.

b DNA sequence immediately at $5^{\prime}$ end of the idiomorph.

' DNA sequence immediately at 3 ' end of the idiomorph. 
ences, respectively, when compared with their counterparts in C. heterostrophus (FIGS. 6, 7).

Molecular characterization of mating types in field isolates of $\mathrm{C}$. sativus.-The MAT-2-specific HMG box cloned from isolate ND90Pr was used as a probe to hybridize with genomic DNA prepared from field isolates of $C$. sativus collected from different regions of the world (TABLE II). Among the 54 Cochliobolus sativus isolates surveyed, 28 showed a hybridization band, which indicated the presence of the MAT-2 homolog. Southern hybridization of the HMG box with genomic DNA of a subset of the C. sativus isolates is shown in Fig. 8a. When the primer pair CsPrimer $1+2$ was used for PCR amplification, the HMG box was only present in these 28 isolates (data not shown), corroborating further the MAT-2 identity of these isolates. When a sub-clone containing a MAT-1 specific fragment from isolate ND93-1 was used as a probe, a hybridization band occurred only in the remaining 26 isolates (FIG. 8b), indicating that they have a MAT-1 homolog.

\section{DISCUSSION}

Our mating type testing experiments showed that most of the C. sativus progeny failed to produce fertile pseudothecia when backcrossed to the parents. This indicates that, in addition to mating type genes, other genetic factors may be involved in the development of the perfect stage in this fungus. In another genetic study, Hosford et al (1975) found that most progeny from a $C$. sativus cross did not produce fertile pseudothecia when crossed with either parent or with each other. They suggested that three genes controlled the events leading to the formation of pseudothecia, asci, and ascospores. Our results agree with those of Hosford et al (1975), since we found that only five of the 51 MAT-1 progeny produced pseudothecia with asci or/and ascospores. This segregation fits a 1:7 ratio $\left(\chi^{2}=0.34, P=0.56\right)$, indicating that three genes might be involved in sexual fertility. No asci were observed among matings with the 53 MAT-2 progeny. This may be due to the extremely low fertility of these progeny because even when some pseudothecia are produced, the low number of asci formed might go undetected when only 20 to 30 pseudothecia-like structures are checked in each cross as was done in this study.

For genetic studies of important characters in fungal pathogens, it is very useful to have compatible isolates that can be crossed with other isolates of interest. However, for many fungi, the perfect stage does not exist or cannot be induced in culture making genetic studies through crossing impossible. Even for fungal pathogens whose perfect stage can be induced in culture, some critical isolates of interest may not be compatible with each other. Such is the case for $C$. sativus. In previous studies, three pathotypes of $C$. sativus inducing differential spot blotch infection responses on three barley genotypes (NDB112, ND5883, and Bowman), were identified (Fetch and Steffenson 1994, Valjavec-Gratian and Steffenson 1997a). Pathotype 1 (represented by isolate ND85F) is highly virulent on barley genotype ND5883, but expresses low virulence on barley genotypes Bowman and NDB112. Pathotype 2 (represented by isolate ND90Pr) is highly virulent on Bowman, but expresses low virulence on ND5883 and NDB112, and pathotype 0 (represented by isolate ND93-1) expresses low virulence on all three barley genotypes (Valjavec-Gratian and Steffenson 1997a). To study the genetics of differential virulence expressed by $C$. sativus isolates ND85F and ND90Pr on barley genotypes Bowman and ND5883, matings were attempted, but all were unsuccessful (Valjavec-Gratian and Steffenson 1997b). Many other mating attempts were made between pathotype 1 and pathotype 2 isolates, but again without success (Valjavec-Gratian and Steffenson 1997b, Valjavec-Gratian and Steffenson unpubl). Cloning and sequencing of a MAT-1 homologue in isolate ND85F indicates that it is $97 \%$ identical to MAT-1 in ND93-1, the isolate that was successfully hybridized to isolate ND90Pr. A key difference in MAT-1 from isolate ND85F is a single base-pair deletion occurring in the region that encodes the alpha domain (S. Zhong and B. Steffenson unpubl). This nucleotide deletion leads to a frame-shift in the $M A T$ 1 specific ORF and premature termination of the protein. It is not known whether this difference in the MAT-1 idiomorph is a major factor contributing to the infertility of matings involving ND85F. Transformation of isolate ND85F with a functioning $M A T$ gene from $C$. heterostrophus or C. sativus, together with tests of fertility of such transformants with various isolates, would clarify this question. Moreover, transformation of a MAT deletion mutant of $C$. heterostrophus or C. sativus with the MAT-1 idiomorph from ND85F would provide information regarding the function of the MAT gene in isolate ND85F. A similar strategy was used to test the function of several MAT genes cloned from C. carbonum, C. victoriae, and Bipolaris sacchari (Sharon et al 1996, Christiansen et al 1997).

Mating type genes have been cloned from different types of fungi, including yeasts (Hicks et al 1979, Kelly et al 1988), filamentous ascomycetes (Glass et al 1988, Picard et al 1991, Turgeon et al 1993, Sharon et al 1996, Christiansen et al 1997) and basidiomycetes (Giasson et al 1989, Kronstad and Leong 1989, 


\section{ClustalW Formatted Alignments}

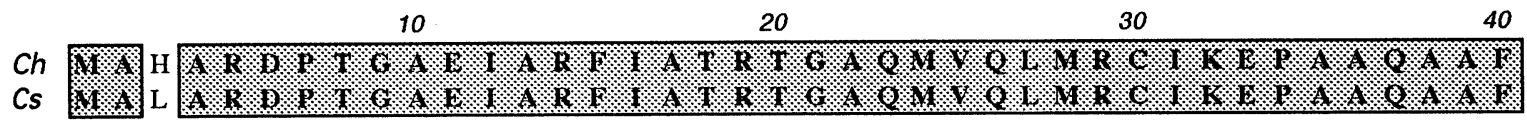

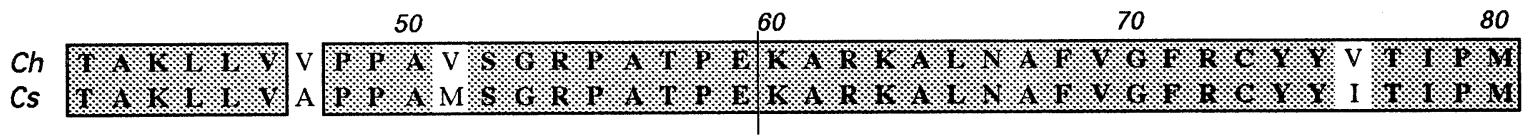

$90 \quad 100 \quad 110 \quad 120$

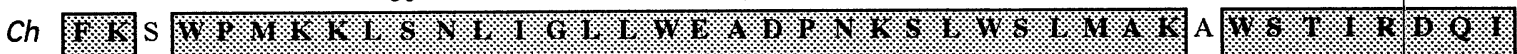

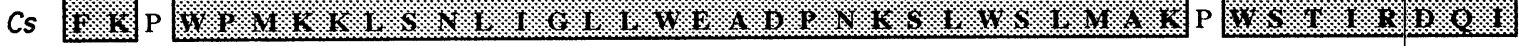

130

140

150

160

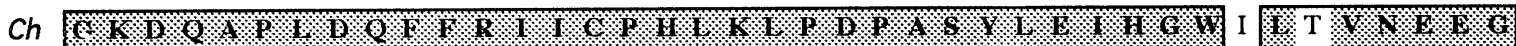

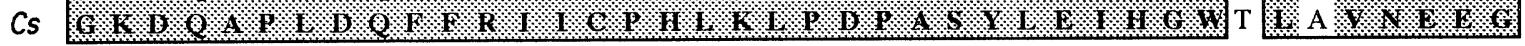

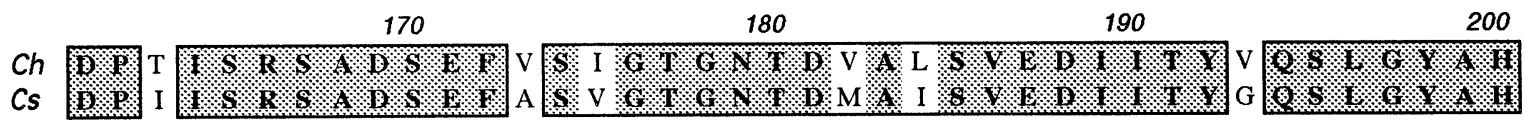

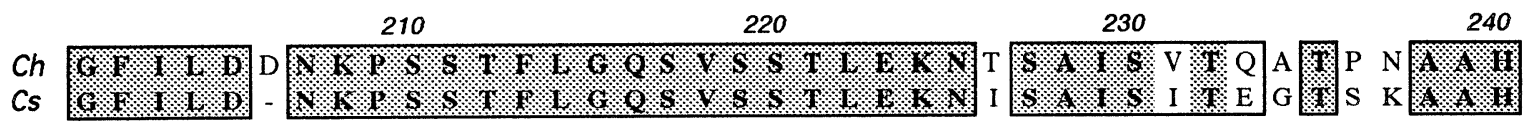

Ch $\begin{array}{ccc}250 & 260 & 270 \\ \text { Cs }\end{array}$

290
Cs

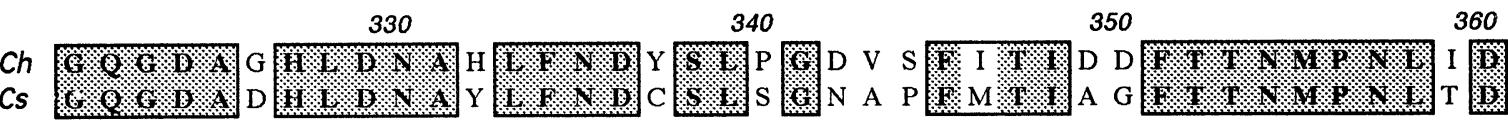

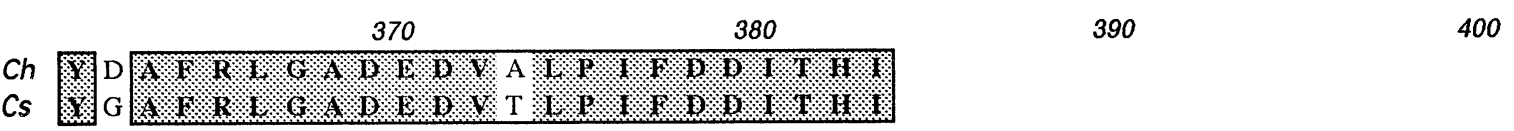

FIG. 6. Alignment of amino acids of the MAT-1 specific ORFs between Cochliobolus sativus (Cs) and C. heterostrophus $(C h)$. Exact matches are shaded, whereas conserved substitutions are boxed but not shaded. The DNA binding domain (alpha box) (from amino acid 60 to 118) is flanked by two vertical lines (l). Note that there are three amino acid differences for the alpha box between the two species.

Mutasa et al 1990). Although no substantial DNA sequence similarity was found among the MAT genes from these different types of fungi, amino acid similarities occur in the DNA binding motifs encoded by the MAT genes. Taking advantage of the highly conserved motifs, Arie et al (1997) developed degenerate primers and amplified DNA binding motif-specific PCR products from most genera of the loculoas- 


\section{ClustalW Formatted Alignments}

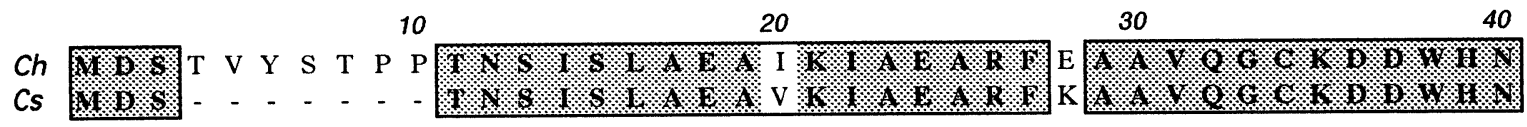

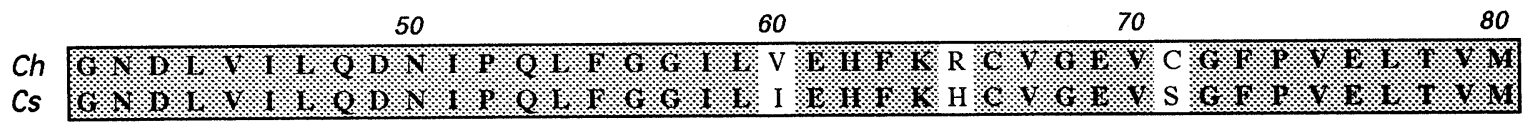

90

100

110

120

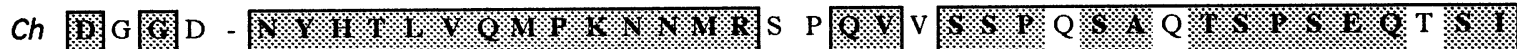

Cs $19 \mathrm{~s}$.

Ch $\begin{gathered}130 \\ \text { Cs }\end{gathered}$

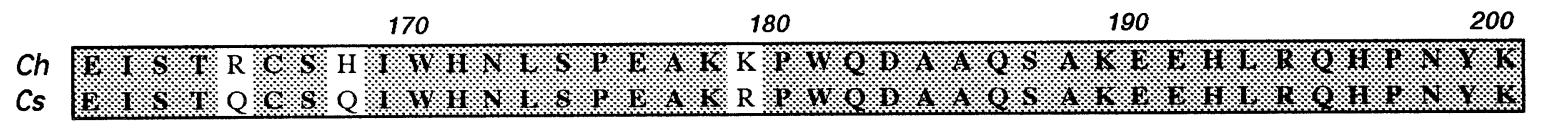

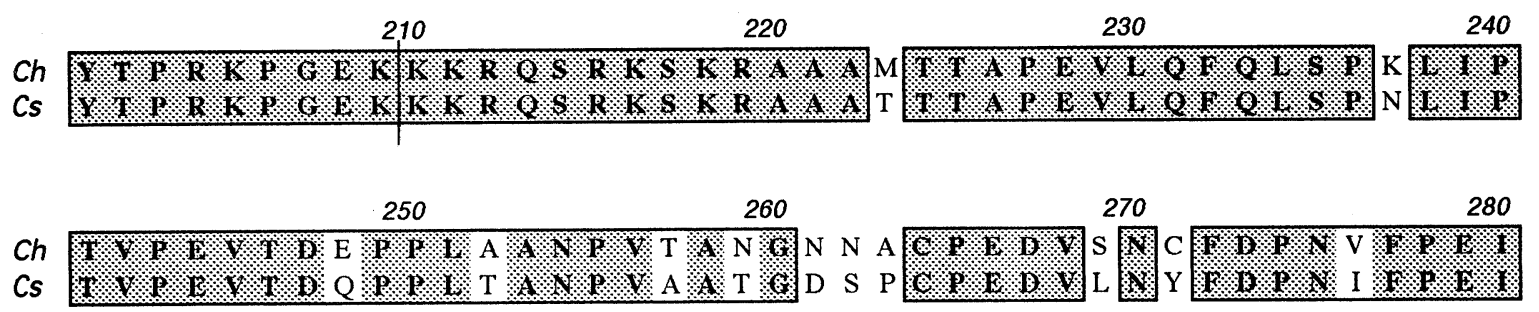

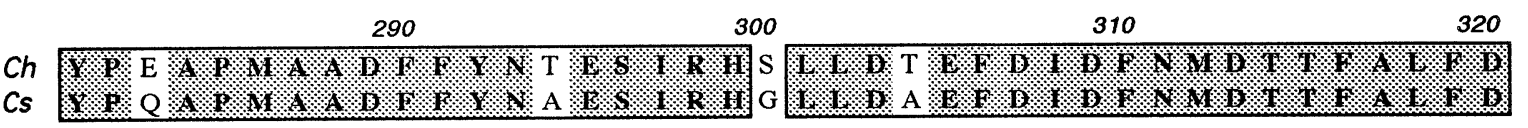

330

340

350

360

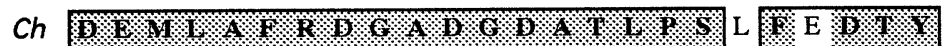

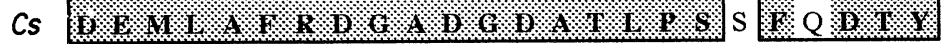

FIG. 7. Alignment of amino acids of the MAT-2 specific ORFs between Cochliobolus sativus (Cs) and C. heterostrophus $(C h)$. Exact matches are shaded, whereas conserved substitutions are boxed but not shaded. The DNA binding domain (HMG domain) (from amino acid 131 to 209) is flanked by two vertical lines (|). Note that there are four amino acid differences for the HMG domain between the two species.

comycetes and pyrenomycetes studied. These specific PCR products could be used as starting points for the cloning of mating type genes in many Ascomycetes by heterologous hybridization or various PCR approaches as demonstrated previously (Yun et al 1999) and in the present study. This same strategy should be applicable for the cloning of MAT genes from other Cochliobolus species and their asexual anamorphs or relatives (e.g., Bipolaris and Curvularia).
Mating types of fungal isolates are usually assessed through pairing with tester isolates of known mating type. This procedure is laborious and time consuming. With the successful cloning of MAT genes from various fungi, it is now possible to characterize the mating type of isolates using a molecular assay. This technique is especially useful in fungal species where low fertility or infertility is common, as with C. sativus (Kline and Nelson 1968, Harding and Tinline 1983, 


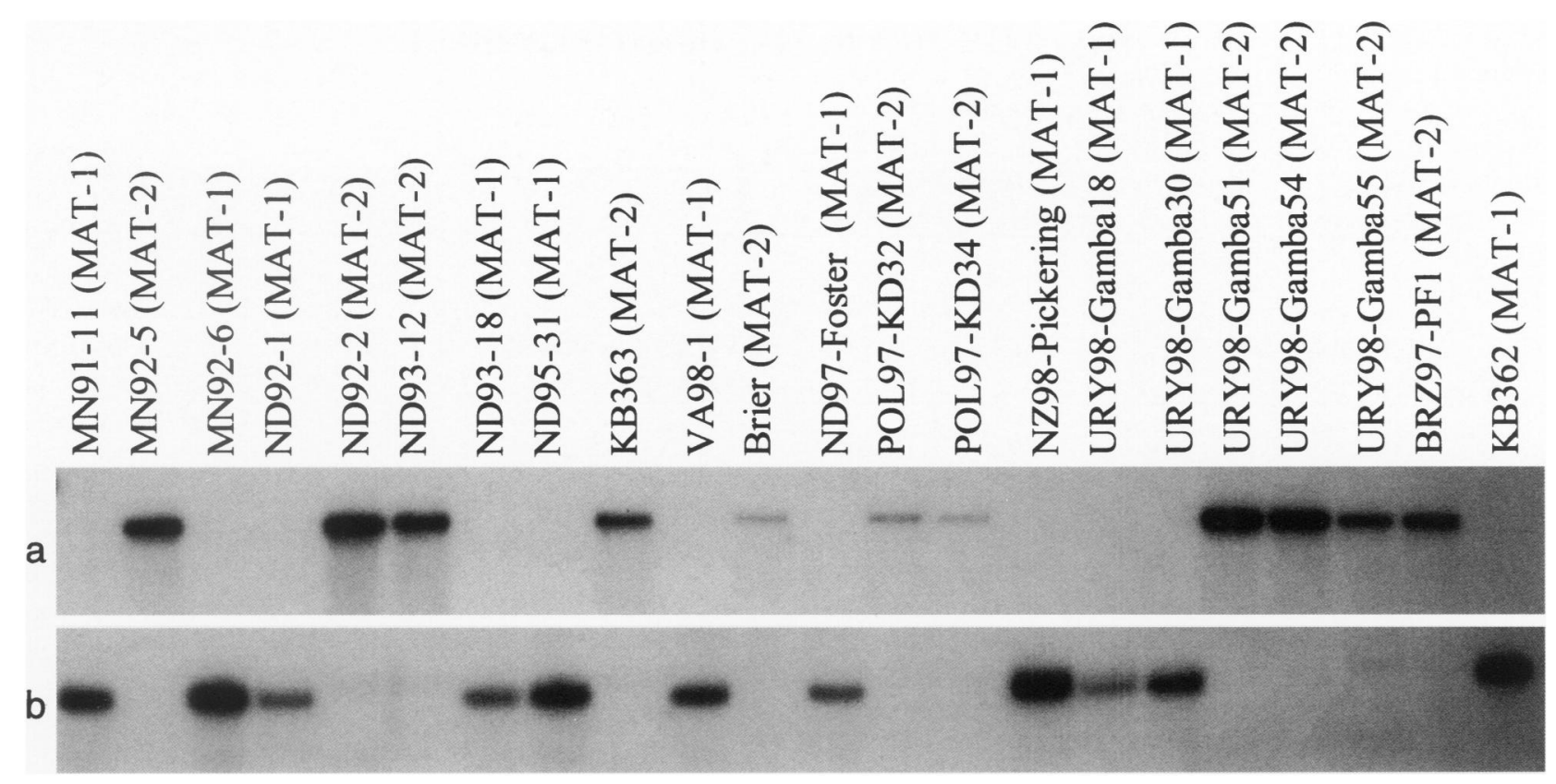

FIG. 8a, b. Hybridization of HMG box and a $0.25 \mathrm{~kb}$ HindIII-EcoRI MAT-1 clone (containing bp1100-1349 of the MAT1 idiomorph) to genomic DNAs of field-collected isolates of Cochliobolus sativus. Genomic DNAs from field isolates of $C$. sativus were digested with EcoRV, separated in a $0.9 \%$ agarose gel, blotted, and probed with the HMG box as a probe (a). After autoradiography, the filter was stripped and reprobed with the $0.25 \mathrm{~kb}$ HindIII-EcoRI MAT-1 clone (b). A subset of $C$. sativus isolates is shown here. Note that MAT-2 isolates show a hybridization band (about $14.5 \mathrm{~kb}$ ) with the HMG box, and MAT-1 isolates show a hybridization band (about $14.8 \mathrm{~kb}$ ) with the $0.25 \mathrm{~kb}$ HindIII-EcoRI clone of the MAT-1 idiomorph.

Valjavec-Gratian and Steffenson 1997b, Zhong and Steffenson unpubl). Based on DNA hybridization and PCR amplification, we have determined the mating type of many $C$. sativus isolates. Within the group of 54 field isolates surveyed, the two mating types occurred with nearly the same frequency $(48 \%$ for MAT-1 and 52\% for MAT-2). Moreover, both mating types occurred in different geographic regions (TABLE II). This result is in agreement with the observation of Harding and Tinline (1983), who identified both mating types in C. sativus populations in Saskatchewan, Canada.

Even though both mating types of $C$. sativus have been identified in the same field or same population, the perfect stage of the fungus has not been found in nature (Tinline 1988). Several factors may prevent the development of the sexual stage in nature. As mentioned previously, many isolates are infertile even when paired with isolates of opposite mating type in culture, suggesting that other genetic factors for fertility are defective or not functioning. Additionally, critical environmental factors may be required for the induction of sexual structures (Tinline 1951, Shoemaker 1955). Further research on MAT genes and other genetic factors affecting fertility will increase our understanding of the mating mechanisms in the fungus.

\section{ACKNOWLEDGMENTS}

We thank O. C. Yoder and B. G. Turgeon for providing the HMG clone amplified from the C. sativus isolate A20 and its DNA sequence. We also appreciate B. G. Turgeon for critically reviewing the manuscript.

\section{LITERATURE CITED}

Altschul SF, Madden TL, Schäffer AA, Zhang J, Zhang Z, Miller W, Lipman DJ. 1997. Gapped BLAST and PSIBLAST: A new generation of protein database search programs. Nucleic Acids Res 25:3389-3402.

Arie T, Christiansen SK, Yoder OC, Turgeon BG. 1997. Efficient cloning of ascomycete mating type genes by PCR amplification of the conserved MAT HMG box. Fungal Genet Biol 21:118-130.

Christiansen SK, Wirsel S, Yun SH, Yoder OC, Turgeon BG. 1997. The two Cochliobolus mating type genes are conserved among species but one of them is missing in C.victoriae. Mycol Res 102:919-921.

Fetch TG, Steffenson BJ. 1994. Identification of Cochliobolus sativus isolates expressing differential virulence on tworow barley genotypes from North Dakota. Can J Plant Pathol 16:202-206.

Giasson L, Specht CA, Milgrim C, Novotny CP, Ullrich RC. 1989. Cloning and comparison of $A a$ mating-type alleles of the Basidiomycete Schizophyllum commune. Mol Gen Genet 218:72-77. 
Glass NL, Vollmer SJ, Staben C, Grotelueschen J, Metzenberg RL, Yanotsky C. 1988. DNAs of the two matingtype alleles of Neurospora crassa are highly dissimilar. Science 241:570-573.

Harding H, Tinline RD. 1983. The existence of differentially fertile strains in two populations of Cochliobolus sativus. Can J Plant Pathol 5:17-20.

Hicks J, Strathern JN, Klar AJS. 1979. Transposable mating type genes in Saccharomyces cerevisiae. Nature 282:478483.

Hosford RM, Solangi GRM, Kiesling RL. 1975. Inheritance in Cochliobolus sativus. Phytopathology 65:699-703.

Kelly M, Burke J, Smith M, Klar A, Beach D. 1988. Four mating-type genes control sexual differentiation in the fission yeast. EMBO J 7:1537-1548.

Kline DM, Nelson RR. 1968. Variation in mating capacities among 103 isolates of Cochliobolus sativus. (Abstr.) Phytopathology 58:1055.

Kronstad JW, Leong SA. 1989. Isolation of two alleles of the $b$ locus of Ustilago maydis. Proc Natl Acad Sci USA 86: 978-982.

Metzenberg RL, Glass NL. 1990. Mating type and mating strategies in Neurospora. Bioassays 12:53-59.

Mutasa ES, Tymon AM, Gottgens B, Mellon FM, Little PFR, Casselton LA. 1990. Molecular organization of an $A$ mating type factor of the basidiomycete fungus Coprinus cinereus. Curr Genet 18:223-229.

Picard M, Debuchy R, Coppin E. 1991. Cloning the mating types of the heterothallic fungus Podospora anserinadevelopmental features of haploid transformants carrying both mating types. Genetics 128:539-547.

Sambrook J, Fritsch EF, Maniatis T. 1989. Molecular cloning: A laboratory Manual. 2nd ed. Cold Spring Harbor, New York: Cold Spring Harbor Laboratory Press. 1530 p.

Sharon A, Yamaguchi K, Christiansen S, Horwitz BA, Yoder OC, Turgeon BG. 1996. An asexual fungus has the po- tential for sexual development. Mol Gen Genet 251:6068.

Shoemaker RA. 1955. Biology, cytology, and taxonomy of Cochliobolus sativus. Can J Bot 33:562-576.

Tinline RD. 1951. Studies on the perfect stage of Helminthosporium sativum. Can J Bot 29:467-480.

Tinline RD. 1988. Cochliobolus sativus, a pathogen of wide host range. In: Ingram DS, Williams PH, eds. Advances in plant pathology. Vol. 6. London, England: Academic Press. p 113-122.

Tinline RD, Dickson JG. 1958. Cochliobolus sativus. I. Perithecial development and inheritance of spore color and mating type. Mycologia 50:697-706.

Turgeon BG, Bohlmann H, Ciuffetti LM, Christiansen SK, Yang G, Schafer W, Yoder OC. 1993. Cloning and analysis of the mating type genes from Cochliobolus heterostrophus. Mol Gen Genet 238:270-284.

Turgeon BG. 1998. Application of mating type gene technology to problems in fungal biology. Annu Rev Phytopathol 36:115-137.

Valjavec-Gratian M, Steffenson BJ. 1997a. Pathotypes of Cochliobolus sativus on barley in North Dakota. Plant Dis. 81:1275-1278.

Valjavec-Gratian M, Steffenson BJ. 1997b. Genetics of virulence in Cochliobolus sativus and resistance in barley. Phytopathology 87:1140-1143.

Wirsel S, Horwitz B, Yamaguchi K, Yoder OC, Turgeon BG. 1998. Single mating type-specific genes and their $3^{\prime}$ UTRs control mating and fertility in Cochiobolus heterostrophus. Mol Gen Genet 259:272-281.

Yoder OC. 1988. Cochliobolus heterostrophus, cause of southern corn leaf blight. In: Ingram DS, Williams PH, eds. Advances in plant pathology. Vol. 6. London, England: Academic Press. p 93-112.

Yun SH, Berbee ML, Yoder OC, Turgeon BG. 1999. Evolution of the fungal self-fertile reproductive life style from self-sterile ancestors. Proc Natl Acad Sci USA 96: 5592-5597. 